\title{
Using Enzymes to Tame Nitrogen-Centered Radicals for Enantioselective Hydroamination
}

Yuxuan Ye ${ }^{1,5}$, Jingzhe Cao ${ }^{1,2,5}$, Daniel G. Oblinsky ${ }^{2}$, Deeptak Verma ${ }^{3}$, Christopher K. Prier ${ }^{4}$, Gregory D. Scholes ${ }^{2} \&$ Todd K. Hyster ${ }^{1,2 *}$

\author{
Affiliations: \\ ${ }^{1}$ Department of Chemistry and Chemical Biology, Cornell University, Ithaca, New York 14853, \\ United States \\ ${ }^{2}$ Department of Chemistry, Princeton University, Princeton, New Jersey 08544, United States \\ ${ }^{3}$ Computational and Structural Chemistry, Merck \& Co., Inc., Rahway, New Jersey, 07065, United \\ States \\ ${ }^{4}$ Department of Process Research and Development, Merck \& Co., Inc., Rahway, New Jersey, \\ 07065, United States \\ ${ }^{5}$ These authors contributed equally: Yuxuan Ye, Jingzhe Cao.
}

\section{Summary Paragraph:}

The construction of $\mathrm{C}-\mathrm{N}$ bonds is essential for the preparation of numerous molecules critical to modern society ${ }^{1,2}$. Nature has evolved enzymes to facilitate these transformations using nucleophilic and nitrene transfer mechanisms ${ }^{3,4}$. However, neither natural nor engineered enzymes are known to generate and control nitrogen-centered radicals, which serve as valuable species for $\mathrm{C}-\mathrm{N}$ bond formation. Herein, we describe a platform for generating nitrogen-centered radicals within protein active sites, thus enabling asymmetric hydroamination reactions. Using flavindependent 'ene'-reductases with an exogenous photoredox catalyst, amidyl radicals are generated selectively within the protein active site. Empowered by directed evolution, these enzymes are engineered to catalyze 5-exo, 6-endo, 7-endo, 8-endo, and intermolecular hydroamination reactions with high levels of enantioselectivity. Mechanistic studies suggest that radical initiation occurs via an enzyme-gated mechanism, where the protein thermodynamically activates the substrate for reduction by the photocatalyst. Molecular dynamics studies suggest that the enzymes bind substrates using non-canonical binding interactions, which may serve as a handle to further 
manipulate reactivity. This approach demonstrates the versatility of these enzymes for controlling the reactivity of high-energy radical intermediates and highlight the opportunity for synergistic catalyst strategies to unlock new enzymatic functions.

\section{Main Text:}

Nitrogen-containing heterocycles are privileged structures for drug design and are found in nearly $75 \%$ of the drugs approved by the FDA and currently available on the market ${ }^{5}$. The importance of this class of compounds has led to the development of countless catalytic methods for their selective preparation. Biocatalysts are becoming increasingly important for the asymmetric synthesis of $N$-heterocycles, given their ability to facilitate chemical transformations with precise control over the reaction's stereochemical outcome. Many enzymes, including transaminases $^{6}$, reductive aminases ${ }^{7,8}, \mathrm{C}-\mathrm{N}$ lyases ${ }^{9-11}$, and acyltransferases ${ }^{12}$, catalyze $\mathrm{C}-\mathrm{N}$ bond formation via mechanisms that exploit the inherent nucleophilicity of amines coupled with the electrophilicity of carbonyls and alkenes (Fig. 1a). Also known, though less common, are metalloenzymes that utilize iron nitrenoids - prepared from oxidized amine precursors—for aziridination and $\mathrm{C}-\mathrm{H}$ insertion reactions (Fig. 1a) ${ }^{13,14}$. While these mechanisms are effective, they represent only a fraction of those available to abiotic catalysts for $\mathrm{C}-\mathrm{N}$ bond formation.

Nitrogen-centered radicals (NCRs) are versatile, high-energy intermediates for hydroamination, $\mathrm{C}-\mathrm{H}$ amination, and hydrogen atom abstraction reactions (Fig. 1a) ${ }^{15-17}$, and because they readily react with unactivated coupling partners, NCRs are attractive for use in chemical synthesis from a variety of starting materials. However, this reactivity comes at a cost as NCRs are readily quenched via reductive mechanisms ${ }^{18}$. These termination events represent a significant impediment to the development of challenging, kinetically slow reactions radical 
amination reactions. Moreover, it remains difficult to design catalysts capable of harnessing NCRs for enantioselective transformations ${ }^{16}$. Given the precedent for enzymatic control of highly reactive intermediates, such as Compound I in $\mathrm{P} 450 \mathrm{~s}{ }^{19}$ and carbon radicals generated by radical $S$ adenosyl-L-methionine (SAM) enzymes ${ }^{20}$, we hypothesized that enzymes could also be used to control NCRs in synthetically useful reactions ${ }^{21}$. However, to the best of our knowledge, no enzymes utilize NCRs in their natural setting.

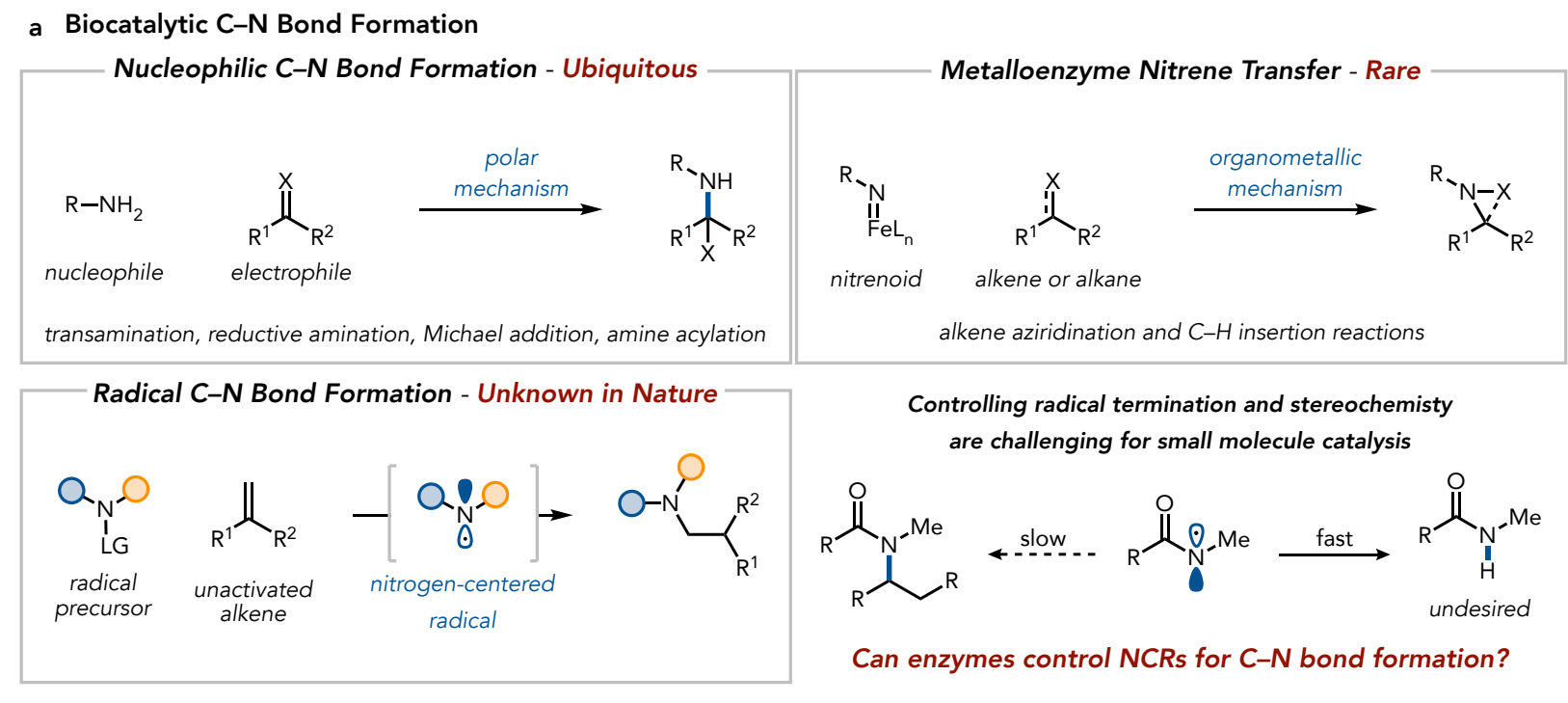

b This Work: Biocatalytic Asymmetric Radical C-N Bond Formation

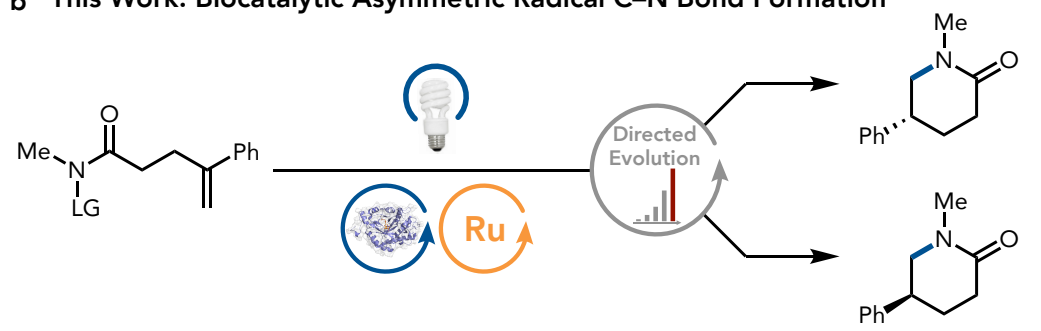

Hydroamination Products<smiles>CN1CC(c2ccccc2)CCCCC1=O</smiles><smiles>COC(CN(C)C(=O)c1ccccc1)c1ccccc1</smiles>

Fig. 1. Biocatalytic radical $\mathbf{C}-\mathbf{N}$ bond forming reactions. a, Enzymatic $\mathrm{C}-\mathrm{N}$ bond formation reactions predominantly rely on polar nucleophilic mechanisms and very few on organometallic mechanisms. Biocatalytic radical $\mathrm{C}-\mathrm{N}$ bond forming reactions would be of great value but are unknown in nature. $\mathbf{b}$, A general photoenzymatic platform enabling biocatalytic radical $\mathrm{C}-\mathrm{N}$ bond formation is realized by the combination of enzymatic catalysis and photoredox catalysis. X, oxygen or carbon atom; L, ligand; LG, leaving group; Me, methyl; Ph, phenyl. 
Over the past several years, our group has developed strategies for forming carbon-centered radicals from organohalides, using flavin-dependent 'ene'-reductases (EREDs) ${ }^{22-26}$. In these reactions, the flavin hydroquinone $\left(\mathrm{FMN}_{\mathrm{hq}}\right)$ cofactor serves as a single electron reductant to form radical intermediates that can engage in $\mathrm{C}-\mathrm{C}$ bond-forming events before reductive radical termination by the flavin semiquinone $\left(\mathrm{FMN}_{\mathrm{sq}}\right)$. Importantly, these results demonstrate the compatibility of EREDs with radical intermediates and the ability of this enzyme family to control the stereochemical outcome of radical reactions ${ }^{27}$. Here, we report our development of an EREDbased photoenzymatic platform capable of harnessing NCRs for $\mathrm{C}-\mathrm{N}$ bond formation (Fig. 1b). With the aid of directed evolution, we demonstrate the versatility of this platform for synergistic bio- and photocatalysis, enabling a wide variety of asymmetric radical hydroamination reactions.

We began by investigating EREDs for catalyzing a 6-endo-trig radical hydroamination. We targeted stable hydroxamic esters as radical precursors due to their compatibility with biocatalytic reaction conditions (Supplementary Table 10) ${ }^{28}$. However, because of their low reduction potentials $\left(E_{1 / 2}>-1.7 \mathrm{~V} \text { versus saturated calomel electrode, } \mathrm{SCE}\right)^{29}$, hydroxamic esters cannot be reduced by ground state $\mathrm{FMN}_{\mathrm{hq}}$ and are not observed to form charge-transfer complexes. To overcome this limitation, we envisioned using direct photoexcitation of $\mathrm{FMN}_{\mathrm{hq}}$ to afford access to a more highly reducing excited state $\left(E_{1 / 2}{ }^{*}=-2.26 \mathrm{~V} \text { versus } \mathrm{SCE}\right)^{30,31}$. Using hydroxamic ester 1 (Fig. 2a) featuring an electron-deficient pentafluorobenzoxyl moiety as our substrate, we evaluated a panel of structurally diverse EREDs (Supplementary Table 1) for their ability to catalyze cyclization under violet light irradiation $\left(\lambda_{\mathrm{em}}=390 \mathrm{~nm}\right)$. Only YqjM, an ERED from Bacillus subtilis, afforded the desired hydroaminated product $(R)-2$ (51:49 er) in observable but very low yield $(<5 \%)$. Inspiration by our previous studies using photoredox catalysts to generate radicals within protein active sites, we tested a series of photocatalysts for this reaction ${ }^{32-34}$. 
Gratifyingly, we found that exposure of 1 to a solution of YqjM in the presence of $1 \mathrm{~mol} \%$ $\mathrm{Ru}(\mathrm{bpy})_{3} \mathrm{Cl}_{2}$ (bpy $=2,2^{\prime}$-bipyridyl $)^{35}$ and subsequent irradiation under blue light $\left(\lambda_{\mathrm{em}}=456 \mathrm{~nm}\right)$ produced the desired product $(R)-2$ in $52 \%$ yield with $81: 19$ er (Fig. 2a, entry 1). Control experiments revealed that the photocatalyst, the cofactor regeneration mix, and light are all crucial to the transformation (Fig. 2a, entries 3-5). Additionally, when $1 \mathrm{~mol} \%$ of $\mathrm{FMN}_{\mathrm{ox}}$ is used in place of YqjM, $\mathbf{2}$ is formed in only 22\% yield as a racemic mixture (Fig. 2a, entry 6). Note that, based on reported binding affinities for enzymes in the Old Yellow family $(1-100 \mathrm{nM})^{36,37}$, this reactivity with free flavin is likely inconsequential in the optimized protocol with YqjM. Importantly, the significantly improved enantioselectivity and activity witnessed with YqjM suggest an enzymegated reduction mechanism that limits radical formation to the active site (vide infra). We also tested other hydroxamic ester substrates with 4-trifluoromethylbenzoyl ( $\left.\mathrm{OBz}_{\mathrm{CF} 3}\right)$ and 4fluorobenzoyl (OBzF) leaving groups and found 1 to be optimal (Fig. 2a, entries 7-8). 
a Reaction Discovery

\begin{tabular}{|c|c|c|c|}
\hline $\mathrm{O}$ & $\begin{array}{r}\text { YajM-WT (1 mo } \\
\begin{array}{r}\mathrm{Ru}(\mathrm{bpyy}){ }_{3} \mathrm{Cl}_{2}(1 \mathrm{~m} \\
\text { cofactor regenerat }\end{array} \\
\mathrm{KPi}(100 \mathrm{mM}, \mathrm{pH} \\
5 \% \mathrm{DMSO}, \text { blue LE }\end{array}$ & 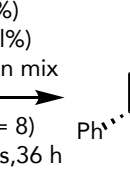 & $\mathrm{Me}$ \\
\hline entry & $\begin{array}{l}\text { variations form } \\
\text { standard conditions }\end{array}$ & yield (\%) & er \\
\hline 1 & none & 52 & $81: 19$ \\
\hline 2 & no $\mathrm{Ru}(\mathrm{bpy})_{3} \mathrm{Cl}_{2}$, violet LEDs & $<5$ & $51: 49$ \\
\hline 3 & no $\mathrm{Ru}(\mathrm{bpy})_{3} \mathrm{Cl}_{2}$ & $<1$ & N.D. \\
\hline 4 & no cofactor regeneration $\mathrm{mi}$ & $<1$ & N.D. \\
\hline 5 & no light & $<1$ & N.D. \\
\hline 6 & $\mathrm{FMN}_{\mathrm{ox}}$ instead of YqjM-WT & 22 & $50: 50$ \\
\hline 7 & 3 instead of 1 & 50 & $81: 19$ \\
\hline 8 & 4 instead of 1 & 18 & $81: 19$ \\
\hline
\end{tabular}

b Proposed Mechanism
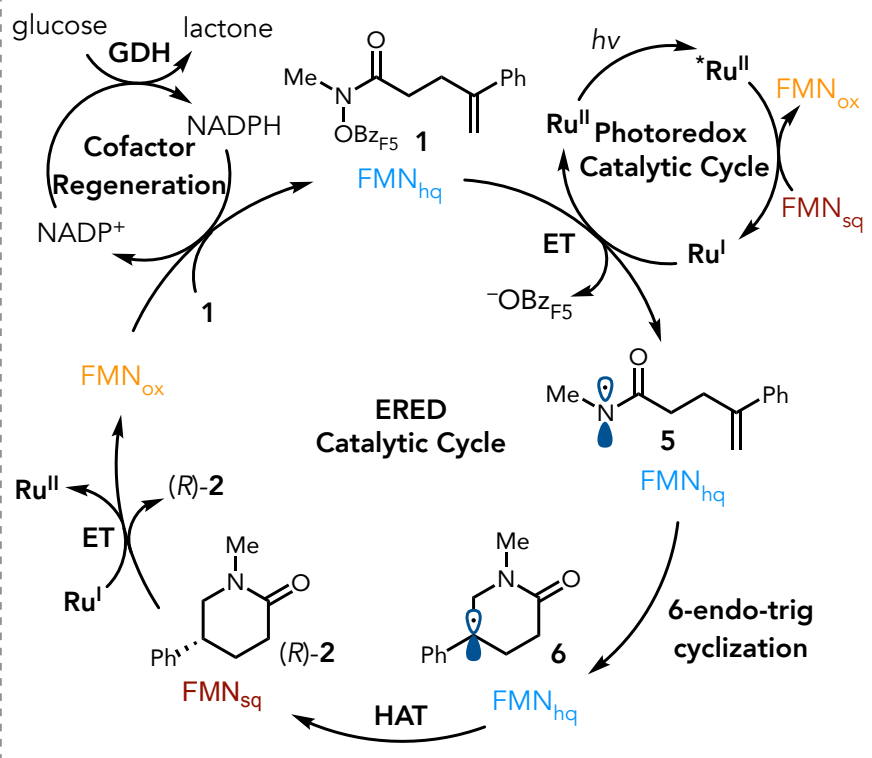

c Directed Evolution of YqjM for Both Enantiomeric Product Formation

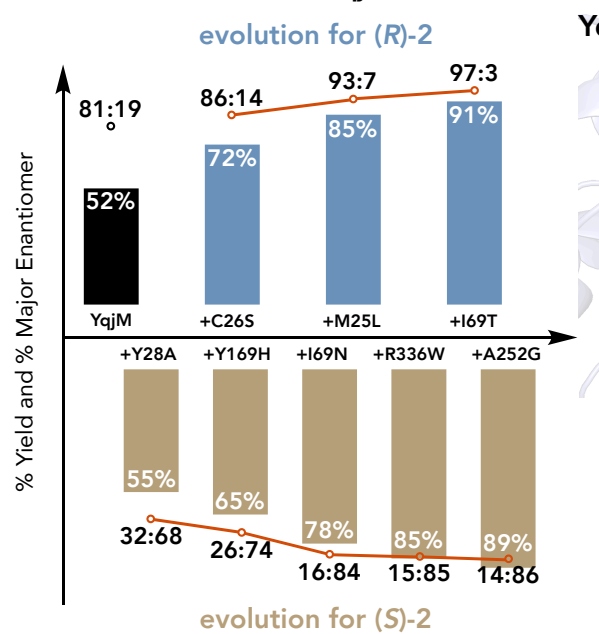

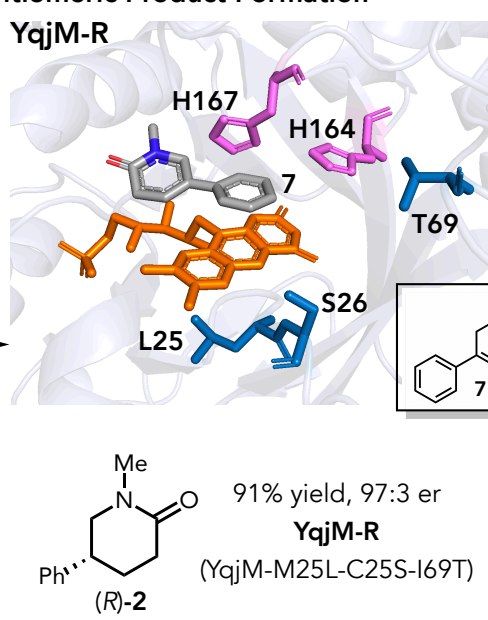

(R)-2
YqjM-S
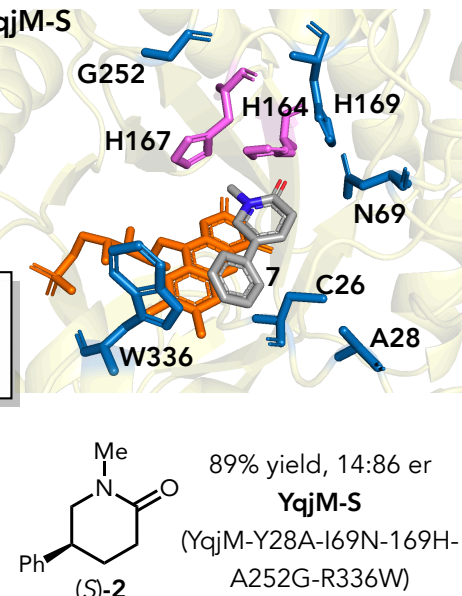

(S)-2

Figure 2. Reaction discovery and directed evolution of YqjM enzyme for intramolecular

hydroamination reaction. a, Evaluation of reaction parameters. For detailed reaction conditions, see the Supplementary Information. b, The starting ester $\mathbf{1}$ is reduced by $\mathbf{R} \mathbf{u}^{\mathbf{I}}$ in the enzyme active site and undergoes sequential 6-endo-trig cyclization and enantiodetermining hydrogen atom transfer (HAT) to afford (R)-2. c, Evolution of YqjM gives access to both enantiomers of 2. Cofactor regeneration mix, $\mathrm{NADP}^{+}(2 \mathrm{~mol} \%)+$ glucose dehydrogenase (GDH-105 from Codexis, $1.5 \mathrm{mg} / \mathrm{mL})+$ glucose (6 equiv.); KPi, potassium phosphate buffer; bpy, 2,2'-bipyridine; DMSO, 
dimethyl sulfoxide; h, hours; er, enantiomeric ratio; N.D., not determined; FMN $\mathrm{ox}_{\mathrm{ox}}$, flavin mononucleotide; FMN $\mathrm{Fq}_{\mathrm{hq}}$, flavin hydroquinone; FMN $\mathrm{sq}$, flavin semiquinone; $\mathrm{OBz}_{\mathrm{CF} 3}$, 4trifluoromethylbenzoyl; OBzF, 4-fluorobenzoyl; ET, electron transfer; HAT, hydrogen atom transfer.

Our proposed mechanism for the hydroamination of $\mathbf{1}$ is shown in Fig. 2b. Under blue light irradiation, $\mathrm{Ru}(\mathrm{bpy})_{3} \mathrm{Cl}_{2}\left(\mathbf{R} \mathbf{u}^{\mathrm{II}}\right)$ is excited to generate the long-lived triplet excited state complex ${ }^{*} \mathbf{R} \mathbf{u}^{\mathrm{II}}\left(E_{1 / 2}{ }^{* \mathrm{II} / \mathrm{I}}=+0.77 \mathrm{~V}\right.$ versus SCE$)$, which is readily reduced to form $\mathrm{Ru}(\mathrm{bpy}){ }_{3}{ }^{+}\left(\mathbf{R u}^{\mathrm{I}}, E_{1 / 2}{ }^{\mathrm{II} / \mathrm{I}}=\right.$ $-1.33 \mathrm{~V}$ versus $\mathrm{SCE})$. The reduced photocatalyst $\mathbf{R} \mathbf{u}^{\mathbf{I}}$ then transfers an electron to enzyme-bound $\mathbf{1}\left(E_{1 / 2} \text { unbound } \mathbf{1}>1.7 \mathrm{~V} \text { versus SCE}\right)^{29}$ to form the NCR intermediate $\mathbf{5}$ and $\mathbf{R} \mathbf{u}^{\mathrm{II}}$, with the loss of benzoate. Here, we reasoned that the enzyme attenuates the reduction potential of $\mathbf{1}$, enabling an otherwise endergonic electron transfer process. Once formed, 5 undergoes 6-endo-trig cyclization to generate intermediate $\mathbf{6}$ with a benzylic radical, and subsequent enantiodetermining hydrogenatom transfer (HAT) from FMN $\mathrm{Fn}_{\mathrm{hq}}$ to 6 affords product $(R)-\mathbf{2}$. The resulting $\mathrm{FMN}_{\mathrm{sq}}\left(E_{1 / 2}=+0.49 \mathrm{~V}\right.$ versus $\mathrm{SCE})^{38}$ undergoes single electron transfer with the excited state $\mathrm{Ru}^{\mathrm{II}}$ photocatalyst to form $\mathrm{FMN}_{\mathrm{ox}}$, which is reduced to $\mathrm{FMN}_{\mathrm{hq}}$ by the cofactor regeneration system, thereby completing both the photoredox and ERED catalytic cycle.

Next, we sought to improve the efficiency and selectivity of this transformation using iterative saturation mutagenesis (ISM) ${ }^{39,40}$ applied to 20 residues lining the active site of YqjM (Supplementary Table 2,3) ${ }^{41}$. After three rounds of protein engineering, we found a triple mutant YqjM-M25L-C26S-I69T (YqjM-R) that facilitates the formation of $(R)-\mathbf{2}$ in 91\% yield with 97:3 er (Fig. 2c). Intriguingly, during the evolution campaign, we noticed that the mutation of tyrosine at position 28 reversed the enantiomeric preference of the enzyme, with Y28A being the most 
effective (32:68 er). We carried out four additional rounds of ISM starting from YqjM-Y28A, focusing on residues lining the active site, and discovered that the quintuple mutant YqjM-Y28AI69N-Y169H-A252G-R336W (YqjM-S) catalyzes the generation of (S)-2 in 89\% yield with 14:86 er (Supplementary Table 4,5).

Molecular dynamics (MD) simulations were performed to elucidate the origin of the enantiocomplementary selectivity of the two YqjM mutants (Fig. 2c). The alkene 7 was chosen as a probe compound, as the styrenyl motif locks the compound into a planar conformation mimicking the benzylic radical intermediate formed prior to the proposed hydrogen atom transfer. MD simulations performed using an existing YqjM structure strikingly revealed flipped binding positions for $\mathbf{7}$ in the YqjM-R and YqjM-S variants, such that both models are consistent with the observed stereochemistry if the $\mathrm{H}$ atom is delivered from the flavin, or the adjacent residue C/S26. The mutation Y28A, which inverts the enantioselectivity of the enzyme, may do so by making space for the phenyl ring of the substrate to sit over the C6 position of the FMN, allowing the flip in orientation of the cyclic intermediate. Also notably, 7 is not bound between the canonical ERED binding residues H164 and H167. In the YqjM-R simulation, the amide carbonyl of 7 does not interact with either residue; in YqjM-S, 7 hydrogen bonds with H167 alone, and only for a portion of the MD run. Instead, water bridges to residue R308 and Y264 contribute to 7 binding in YqjM$\mathbf{R}$, while a hydrophobic interaction with the newly introduced residue W336 contributes prominently to binding in YqjM-S. These models point to novel interactions guiding substrate positioning during HAT and suggest that these enzymes may be further engineered to reinforce these new binding modes.

Having demonstrated that we can optimize the product yield and enantiopurity using YqjM-R or YqjM-S, we set out to investigate the substrate tolerance of these systems (Fig. 3a). 
Both enantiomers of a variety of 5-phenylpiperidin-2-one derivatives with para-, meta-, and orthosubstituents on the aromatic ring were efficiently prepared in high yields and with good levels of enantioselectivity (8 to $\mathbf{2 0}$ ), and furan (21), thiophene (22), and pyridine (23) heterocycles were also accessible. In addition to 5-phenylpiperidin-2-ones, the reaction afforded 5-methyl piperidine2-one (24) in good yield, albeit with a low level of enantioselectivity. By testing a small panel of beneficial mutants obtained during the evolution campaign for $\mathbf{1}$, we further identified the mutant YqjM-Y28G-Y169F, which promotes the formation of piperidines $(\mathbf{2 5}, \mathbf{2 6}$, and 27) from suitable $N$-acetyl acyclic precursors (Supplemental Table 6). In addition, YqjM-Y28C-I69V and YqjMY28C mutants were found to catalyze 5-exo-trig cyclization to generate pyrrolidinone (29; $71 \%$ yield with 52:48 er) and pyrrolidine (31; 36\% yield with 75:25 er), respectively (Supplemental Table 7,8). Notably, the enantiodetermining step in these reactions is $\mathrm{C}-\mathrm{N}$ bond formation rather than hydrogen atom transfer.

The evolvable yields and enantioselectivities demonstrated here encouraged us to investigate transformations of even more complex substrates. We found that in addition to 6-endotrig and 5-exo-trig cyclizations, YqjM-R is capable of catalyzing 7-endo-trig and 8-endo-trig cyclizations to generate $\eta-(\mathbf{3 3})$ and $\theta-(\mathbf{3 5})$ lactams. Importantly, these cyclizations do not occur efficiently in solution when only $\mathrm{FMN}_{\mathrm{ox}}$ is used in place of the enzyme (Supplemental Table 9), highlighting the utility of EREDs for facilitating slow intramolecular hydroamination reactions. We also tested YqjM-R with a simple benzoyl hydroxamic ester starting material and found that, under the optimized photocatalytic conditions, this mutant provides the product in 53\% yield, with no change in enantioselectivity 97:3 er. Finally, the reaction can be run on a preparative scale $(0.1$ mmol) to provide $(R)-\mathbf{2}$ in 78\% yield with 97:3 er (Supplemental Information, Part V). 
Importantly, our method can also be applied to more challenging intermolecular radical hydroamination reactions (Fig. 3b). From a panel of structurally diverse EREDs, we found that GluER-T36A (derived from Gluconobacter oxydans) is effective for the formation of product 36, in $11 \%$ yield from a benzhydroxamic ester and $\alpha$-methyl styrene. Two rounds of iterative sitesaturation mutagenesis yielded the triple mutant GluER-T36A-T231A-G270A, which was found to afford product with improved yield and enantioselectivity (31\% yield, 97:3 er) (Supplemental Table 11,12). This variant was also effective for intermolecular radical hydroamination of 3bromobenzhydroxamic ester with $\alpha$-methyl styrene (37). Other olefins including $\alpha$-methyl vinyl pyridine and $\alpha$-methoxy styrene were tolerated as well, forming products (38 and $\mathbf{3 9}$ ) in moderate yield and with excellent enantioselectivity. 
a<smiles>C=C(O)CCC(=O)N(C)OCc1ccccc1</smiles>

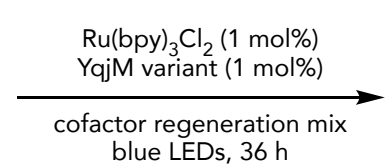<smiles>CN1CC(O)CCC1=O</smiles>
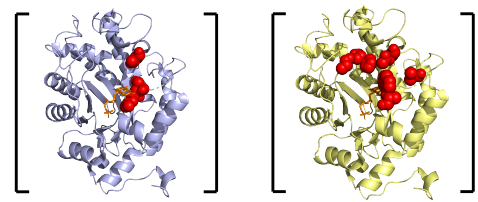

6-endo-trig

YqjM-R

YqjM-S

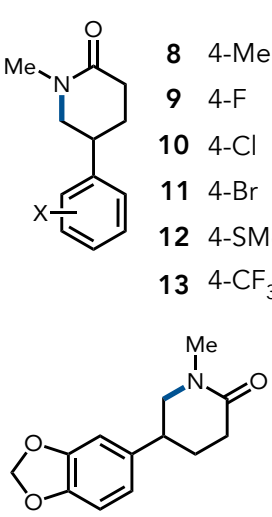

20

(R) $54 \%$ yield, $95: 5$ er (S) $51 \%$ yield, $14: 86$ er

\section{R-Selective}

$75 \%$ yield, $97: 3$ er $82 \%$ yield, $97: 3$ er $71 \%$ yield, $97: 3$ er $55 \%$ yield, $96: 4$ er $84 \%$ yield, $96: 4$ er $48 \%$ yield, $95: 5$ er

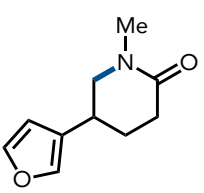

21

\section{S-Selective}

$72 \%$ yield, 8:92 er $78 \%$ yield, $13: 87$ er $65 \%$ yield, $13: 87$ er $51 \%$ yield, $22: 78$ er $71 \%$ yield, $23: 77$ er $44 \%$ yield, $14: 86$ er
R-Selective

S-Selective

$14 \quad 4-\mathrm{OCF}_{3} \quad 64 \%$ yield, 97:3 er $\quad 58 \%$ yield, 12:88 er

$153-\mathrm{OMe} \quad 75 \%$ yield, $97: 3$ er $76 \%$ yield, 20:80 er

$163-\mathrm{CN} \quad 75 \%$ yield, $95: 5$ er $66 \%$ yield, $40: 60$ er

$173-\mathrm{CO}_{2} \mathrm{Me} 92 \%$ yield, $90: 10$ er $77 \%$ yield, $45: 55$ er

18 2-Me $\quad 67 \%$ yield, 92:8 er $63 \%$ yield, 28:72 er

$192-\mathrm{F} \quad 74 \%$ yield, $97: 3$ er $\quad 85 \%$ yield, $27: 73$ er
Exo-Amide

(R) $53 \%$ yield, $93: 7$ er

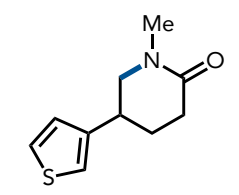

22<smiles>COc1ccc(C2CCC(=O)N([N+](=O)[O-])C2)cn1</smiles>

23

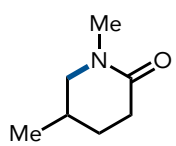

24
(S) $45 \%$ yield, $24: 76$ er

(R) $57 \%$ yield, $91: 9$ er (S) $52 \%$ yield, $30: 70$ er

$74 \%$ yield, $52: 48$ er (S) $66 \%$ yield, 19:81 er 7-endo-trig<smiles>[X]c1ccc([C@H]2CCCN(C(C)=O)C2)cc1</smiles>

$25(\mathrm{X}=\mathrm{H})$ $84 \%$ yield, $89: 11$ er

$26(\mathrm{X}=\mathrm{Cl})$ $81 \%$ yield, 83:17 er

$27(X=E t)$ $66 \%$ yield, $80: 20$ er 5-exo-trig Starting Material<smiles>CN(C(=O)O)C(=O)CC/C=C\c1ccccc1</smiles>

$71 \%$ yield, 52:48 er<smiles>CC(=O)N(CCC/C=C/c1ccccc1)C(C)=O</smiles>

$36 \%$ yield, $75: 25$ er

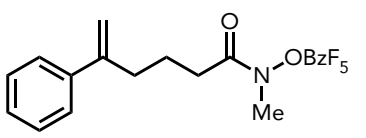

32<smiles>CN1C[C@H](c2ccccc2)CCCC1=O</smiles>

33

74\% yield, 75:25 er

Product $g$ 8-endo-trig
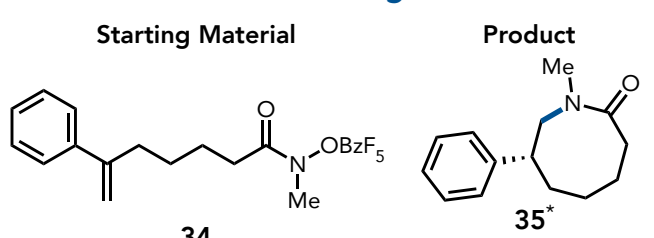

$41 \%$ yield, $54: 46$ er

b

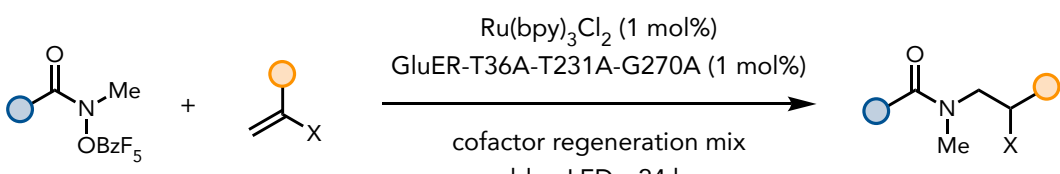

$$
\begin{aligned}
& \text { blue LEDs, } 24 \mathrm{~h}
\end{aligned}
$$

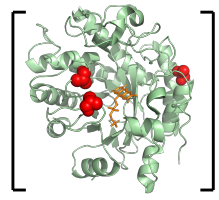

GluER-inter<smiles>CC(CN(C)C(=O)c1ccccc1)c1ccccc1</smiles>

36

$31 \%$ yield, $97: 3$ er<smiles>[M]C(CN(C)C(=O)CCCCCCCCCCCCCC)c1ccccc1</smiles>

37

$45 \%$ yield, $>99: 1$ er<smiles>CC(CN(C)C(=O)c1ccccc1)c1ccccn1</smiles>

38 $32 \%$ yield, $70: 30$ er
$\mathrm{X}=\mathrm{OMe}$<smiles>CO[C@H](CN(C)C(=O)c1ccccc1)c1ccccc1</smiles>

39

$42 \%$ yield, $99: 1$ er 
Figure 3. Scope of biocatalytic radical hydroamination. Red spheres in enzyme cartoons represent sites of mutation. a, 6-endo-trig, 5-exo-trig, 7-endo-trig, and 8-endo-trig cyclizations realized with YqjM catalysts. The reaction conditions were as follows: substrate (1 equiv, $20 \mathrm{mM}$ ), YqjM variant (1 mol\%), Ru(bpy) ${ }_{3} \mathrm{Cl}_{2}(1 \mathrm{~mol} \%), \mathrm{NADP}^{+}(2 \mathrm{~mol} \%), \mathrm{GDH}-105$ (1.5 mg/mL), glucose (6 equiv.), KPi buffer (100 mM, pH 8.0), dimethylsulfoxide (DMSO, 5\% v/v), $460 \mathrm{~nm}$, $25{ }^{\circ} \mathrm{C}, 36 \mathrm{~h}$. For products marked with asterisks, $1.5 \mathrm{~mol} \%$ of YqjM variant was used. b, Intermolecular hydroamination using GluER catalysts. The reaction conditions were as follows: substrate (1 equiv, $20 \mathrm{mM})$, olefin ( 3 equiv), GluER variant $(1 \mathrm{~mol} \%), \mathrm{Ru}(\mathrm{bpy}){ }_{3} \mathrm{Cl}_{2}(1 \mathrm{~mol} \%)$, $\mathrm{NADP}^{+}$(2 mol\%), GDH-105 (1.5 mg/mL), glucose (6 equiv.), KPi buffer (100 mM, pH 8.0), acetonitrile $(\mathrm{MeCN}, 10 \% \mathrm{v} / \mathrm{v}), 460 \mathrm{~nm}, 25^{\circ} \mathrm{C}, 24 \mathrm{~h}$. Et, ethyl; $m$ - $\mathrm{BrC}_{6} \mathrm{H}_{4}, 3$-bromophenyl; X, methyl or methoxyl group.

We conducted a series of experiments to elucidate the nuances of the reactivity enabled by this enzyme platform, using $\mathbf{1}$ as a model substrate. Transient absorption spectroscopy was used initially to study the electron transfer events involved in the reaction. A solution of the model enzyme YqjM-R was prepared in the presence of the cofactor turnover system and $\mathrm{Ru}(\mathrm{bpy}){ }_{3} \mathrm{Cl}_{2}$, and excitation of this solution at $425 \mathrm{~nm}$ led to the appearance of a spectral signature consistent with the reduced species $\mathrm{Ru}(\mathrm{bpy})_{3}{ }^{+}$. When the same reaction was run in the presence of benzhydroxamic ester $\mathbf{1}$, the $\mathrm{Ru}($ bpy $) 3^{1+}$ signal rapidly decayed with a rate constant of $1.9 \times 10^{6}$ $\mathrm{M}^{-1} \mathrm{~s}^{-1}$, concomitant with the growth of a spectrum consistent with the $\mathrm{FMN}_{\mathrm{sq}}$. Importantly, these spectral changes were only observed in the presence of substrate, suggesting that $\mathrm{Ru}(\mathrm{bpy}) 3^{1+}$ reduces the substrate and the resulting radical is terminated by the $\mathrm{FMN}_{\mathrm{hq}}$ to generate the $\mathrm{FMN}$ sq. 
Given the low reduction potential of benzylic radicals $\left(E_{1 / 2}<-1.43 \mathrm{~V} \text { versus SCE}\right)^{42}$, we hypothesized that radical termination within the protein active site occurs via hydrogen atom transfer, rather than stepwise reduction and protonation. To investigate this step further, we compared the extent of deuterium incorporation in product $\mathbf{2}$ following conversion of $\mathbf{1}$ using YqjM variants and either deuterium-labeled $\mathrm{FMN}_{\mathrm{hq}}$ (using glucose- $d_{l}$ as a source of deuterium) in aqueous buffer, or native $\mathrm{FMN}_{\mathrm{hq}}$ in $\mathrm{D}_{2} \mathrm{O}$ buffer (Fig. 4a). With YqjM-S, when the cofactor was labeled, the lactam was produced in $61 \%$ yield (19:81 er) with $0 \%$ deuterium incorporation at the benzylic position. When the reaction was carried out in $\mathrm{D}_{2} \mathrm{O}$ with native $\mathrm{FMN}_{\mathrm{hq}},(S)-2$ was generated in $60 \%$ yield (17:83 er) with $71 \%$ deuterium incorporation. These results are consistent with radical termination occurring via hydrogen atom transfer from $\mathrm{C} 26$, which sits directly adjacent to the FMN on the same face of the substrate, and subsequent reduction of the thiyl radical by $\mathrm{FMN}_{\mathrm{hq}}$.

Interestingly, when the analogous experiment was conducted with substate 1, YqjM-R, and deuterated $\mathrm{FMN}_{\mathrm{hq}}, 21 \%$ deuterium incorporation was observed in $(R)$-2, whereas using native FMN $N_{\text {hq }}$ with $\mathrm{D}_{2} \mathrm{O}$ resulted in $19 \%$ deuterium incorporation in the product. These results suggest two competing mechanisms of radical termination. One mechanism involves hydrogen atom transfer from $\mathrm{FMN}_{\mathrm{hq}}$, while the other implicates radical termination via a proton-coupled electron transfer (PCET) ${ }^{43,44}$ where a water molecule or side chain of serine (S26) functions as the proton source and $\mathrm{FMN}_{\mathrm{hq}}$ as a reductant. A kinetic isotope effect in the radical termination event is consistent with these results.

Although the deuterium-labeling experiment indicated that the hydrogen atom transfer step in YqjM-R is complicated, we conducted a similar experiment using deuterium labeled $\mathrm{FMN}_{\mathrm{hq}}$ in the intermolecular hydroalkylation to prepare 36 (Supplementary Information Part VI) and in this 
case, $76 \%$ deuterium incorporation was observed. When the reaction was conducted in $\mathrm{D}_{2} \mathrm{O}$ with native $\mathrm{FMN}_{\mathrm{hq}}, 0 \%$ deuterium incorporation was obtained. These results indicate that flavin is responsible for radical termination in these reactions.

A fascinating feature of the reactivity studied here is the role the enzyme plays in activating substrates for reduction. Because the complexity of these reactions precludes the direct comparison of initial rates with and without the protein scaffold, we designed a competition experiment to probe differences in reactivity, following a previously established approach (Fig. 4c ${ }^{45}$. In brief, by analyzing the erosion of the enantiomeric ratio of $\mathbf{2}$ formed under optimized conditions in the presence of increasing amounts of free FMN (one to 15 equivalents relative to bound FMN), we were able to estimate the relative rates of catalysis by free FMN versus protein-bound FMN (Supplementary Information, Part VII). Our results reveal that YqjM-R and YqjM-S accelerate hydroamination of $\mathbf{1}$ to $(R)-\mathbf{2}$ and $(S)-\mathbf{2}$ by nine and 30 fold, respectively, compared to free flavin, consistent with the protein scaffold activating the substrate for the reduction event. Enzymes are known to use a variety of hydrogen bonding, steric, electrostatic, and electric field effects to precisely control electron transfer events ${ }^{46}$. A combination of these effects is likely responsible for controlling electron transfer between the exogenous photocatalyst and substrate within the enzyme active site. 


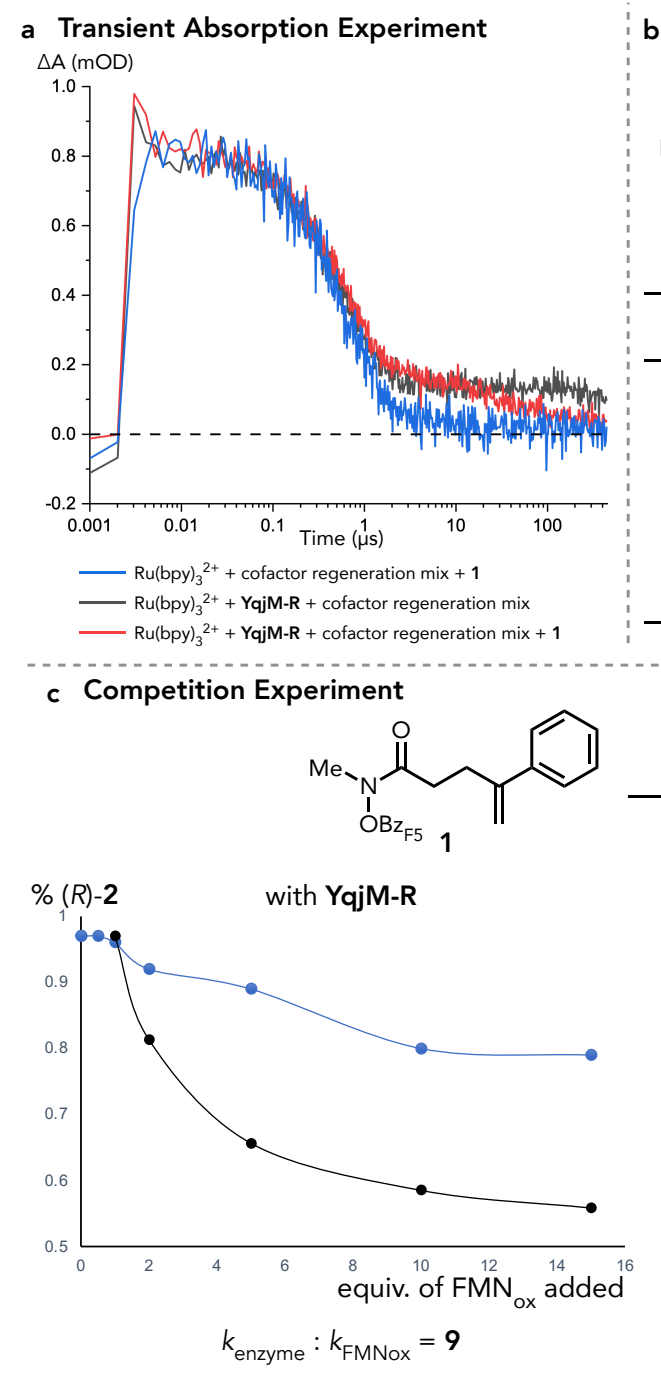

b Deuterium Incorporation Experiment

\begin{tabular}{lll}
\hline enzyme & labeling & results \\
\hline
\end{tabular}

YqjM-S $\quad$ FMN $_{\text {hq }}\left(\right.$ glucose- $\left.d_{1}\right) \quad 61 \%$ yield, 19:81 er, 0\% D-incorporation

$\begin{array}{lll}\text { YqjM-R } & \left.\text { FMN }_{\text {hq }} \text { (glucose- } d_{1}\right) & 52 \% \text { yield, 90:10 er, 21\% D-incorporation } \\ & \text { Buffer }\left(D_{2} O\right) & 62 \% \text { yield, 92:8 er, 19\% D-incorporation }\end{array}$
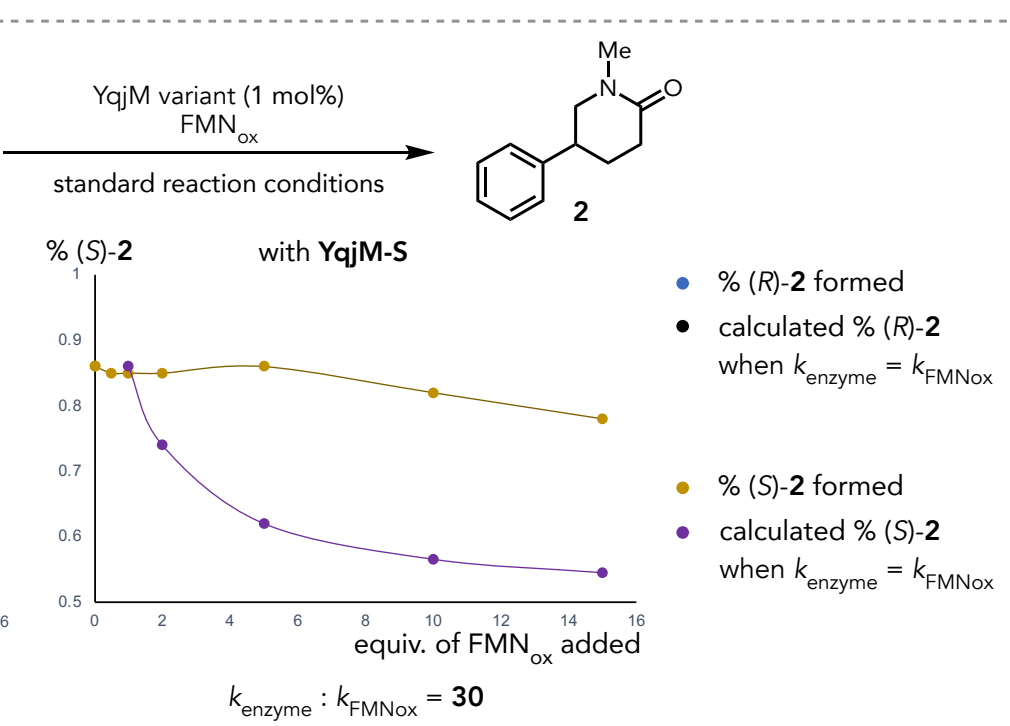

Figure 4. Mechanistic Studies. a, Results of deuterium-labeling experiments used to probe HAT in 6-endo-trig cyclization of $\mathbf{1}$. b, Competition experiments were performed by adding increasing amounts of free $\mathrm{FMN}_{\mathrm{ox}}$ to the standard reaction conditions and measuring the erosion of the enantiomeric ratio of $\mathbf{2}$.

In conclusion, we have developed a novel photoenzymatic platform to initiate and control reactions involving highly reactive nitrogen-centered radicals, and by harnessing the power of directed evolution for enhancing promiscuous activity in EREDs, we have demonstrated the generality of the method to intra- (5-exo, 6-endo, 7-endo, and 8-endo) and intermolecular 
hydroamination reactions. These results highlight the ability of enzymes to precisely control reactive radical intermediates that are challenging to manipulate using contemporary small molecule methods and expand the types of reactivity intermediates available to enzymes.

Online content. Methods, along with any additional Extended Data display items and Source Data, are available in the online version of the paper; references unique to these sections appear only in the online paper.

Data Availability The data that support the findings in this study are available from the corresponding author upon reasonable request.

1. Breuer, M. et al. Industrial Methods for the Production of Optically Active Intermediates. Angew. Chem. Int. Ed. 43, 788-824 (2004).

2. Roughley, S. D., Jordan, A. M. The Medicinal Chemist's Toolbox: An Analysis of Reactions Used in the Pursuit of Drug Candidates. J. Med. Chem. 54, 3451-3479 (2011).

3. Ghislieri, D. \& Turner, N. J. Biocatalytic Approaches to the Synthesis of Enantiomerically Pure Chiral Amines. Top. Catal. 57, 284-300 (2014).

4. Yang, Y. \& Arnold, F. H. Navigating the Unnatural Reaction Space: Directed Evolution of Heme Proteins for Selective Carbene and Nitrene Transfer. Acc. Chem. Res. 54, 1209$1224(2021)$.

5. Kerru, N., Gummidi, L., Maddila, S., Gangu, K. K. \& Jonnalagadda, S. B. A Review on Recent Advances in Nitrogen-Containing Molecules and Their Biological Applications. Molecules. 25, 1909 (2020). 
6. Slabu, I. S., Galman J. L., Lloyd, R. C. \& Turner, N. J. Discovery, Engineering, and Synthetic Application of Transaminase Biocatalysts. ACS Catal. 7, 8263-8284 (2017).

7. Aleku, G. A. et al. A Reductive Aminase from Aspergillus Oryzae. Nat. Chem. 9, 961-969 (2017).

8. Marshall, J. R. et al. Screening and Characterization of a Diverse Panel of Metagenomic Imine Reductases for Biocatalytic Reductive Amination. Nat. Chem. 13, 140-148 (2021).

9. Parmeggiani, F., Weise, N. J., Ahmed, S. T. \& Turner, N. J. Synthetic and Therapeutic Applications of Ammonia-Lyases and Aminomutases. Chem. Rev. 118, 73-118 (2018).

10. Raj, H. et al. Engineering Methylaspartate Ammonia Lyase for the Asymmetric Synthesis of Unnatural Amino Acids. Nat. Chem. 4, 478-484 (2012).

11. Fu, H. et al. Chemoenzymatic Asymmetric Synthesis of the Metallo- $\beta$-Lactamase Inhibitor Aspergillomarasmine A and Related Aminocarboxylic Acids. Nat. Chem. 1, 186-191 (2018).

12. Peatzold J. \& Bäckvall J. E. Chemoenzymatic Dynamic Kinetic Resolution of Primary Amines. J. Am. Chem. Soc. 127, 17620-17621 (2005).

13. Athavale, S. V. et al. Biocatalytic, Intermolecular $\mathrm{C}-\mathrm{H}$ Bond Functionalization for the Synthesis of Enantioenriched Amides. Angew. Chem. Int. Ed. 60, 24864-24869 (2021).

14. Farwell, C. C., Zhang, R. K., McIntosh, J. A., Hyster, T. K. \& Arnold, F. H. Enantioselective Enzyme-Catalyzed Aziridination Enabled by Active-Site Evolution of a Cytochrome P450. ACS Cent. Sci. 1, 89-93 (2015).

15. Zard, S. Z. Recent Progress in the Generation and Use of Nitrogen-Centered Radicals. Chem. Soc. Rev. 37, 1603-1618 (2008). 
16. Kwon, K., Simons, R. T., Nandakumar, M. \& Roizen J. L. Strategies to Generate NitrogenCentered Radicals That May Rely on Photoredox Catalysis: Development in Reaction Methodology and Applications in Organic Synthesis. Chem. Rev. DOI: 10.1021/acs.chemrev.1c00444.

17. Studer, A. \& Curran D. P. Catalysis of Radical Reactions: A Radical Chemistry Perspective. Angew. Chem. Int. Ed. 55, 58-102 (2016).

18. Horner J. H., Musa, O. M., Bouvier, A., Newcomb, M. Absolute Kinetics of Amidyl Radical Reactions. J. Am. Chem. Soc. 120, 7738-7748 (1998).

19. Rittle J. \& Green M. T. Cytochrome P450 Compound I: Capture, Characterization, and CH Bond Activation Kinetics. Science 330, 933-937 (2010).

20. Yokoyama K. \& Lilla E. A. C-C Bond Forming Radical SAM Enzymes Involved in the Construction of Carbon Skeletons of Cofactors and Natural Products. Nat. Prod. Rep. 35, 660-694 (2018).

21. Ye, Y., Fu, H. \& Hyster, T. K. Activation Modes in Biocatalytic Radical Cyclization Reactions. J. Ind. Microbiol. Biotechnol. 48, kuab021 (2021).

22. Biegasiewicz, K. F. et al. Photoexcitation of Flavoenzymes Enables a Stereoselective Radical Cyclization. Science 364, 1166-1169 (2019).

23. Black, M. J. et al. Asymmetric Redox-Neutral Radical Cyclization Catalyzed by FlavinDependent 'ene'-Reductases. Nat. Chem. 12, 71-75 (2020).

24. Clayman, P. D. \& Hyster, T. K. Photoenzymatic Generation of Unstabilized Alkyl Radicals: An Asymmetric Reductive Cyclization. J. Am. Chem. Soc. 142, 15673-15677 (2020).

25. Fu, H. et al. Ground-State Electron Transfer as an Initiation Mechanism for Biocatalytic C-C Bond Forming Reactions. J. Am. Chem. Soc. 143, 9622-9629 (2021). 
26. Page, C. G. et al. Quaternary Charge-Transfer Complex Enables Photoenzymatic Intermolecular Hydroalkylation of Olefins. J. Am. Chem. Soc. 143, 97-102 (2020).

27. Grosheva, D. \& Hyster, T. K. Light-Driven Flavin-Based Biocatalysis. in Flavin-Based Catalysis: Principles and Applications (eds. Cibulka, R., Fraaige, M.) 291-313 (WileyVCH Verlang GmbH \& Co. KGaA 2021).

28. Davies, J. Morcillo, S. P. Douglas, J. J. \& Leonori, D. Hydroxylamine Derivatives as Nitrogen-Radical Precursors in Visible-Light Photochemistry. Chem. Eur. J. 24, 12154$12163(2018)$.

29. Keum, H., Jung, H., Jeong, J., Kim, D. \& Chang, S. Visible-Light Induced C(sp²)-H Amidation with an Aryl-Alkyl $\sigma$-Bond Relocation via Redox-Neutral Radical-Polar Crossover. Angew. Chem. Int. Ed. 60, 1-7 (2021).

30. Warren, J. J., Ener, M. E., Vlček, A. Winkler, J. R. \& Gray, H. B. Electron Hopping Through Proteins. Coord. Chem. Rev. 256, 2478-2487 (2012).

31. Sandoval, B. A. et al. Photoenzymatic Reductions Enabled by Direct Excitation of FlavinDependent ‘Ene'-Reductases. J. Am. Chem. Soc. 143, 1735-1739 (2021).

32. Biegasiewicz, K. F., Cooper, S. J., Emmanuel, M. A., Miller, D. C. \& Hyster, T. K. Catalytic Promiscuity Enabled by Photoredox Catalysis in Nicotinamide-Dependent Oxidoreductases. Nat. Chem. 10, 770-775 (2018).

33. Sandoval, B. A., Kurtoic, S. I., Chung, M. M., Biegasiewicz, K. F. \& Hyster, T. K. Photoenzymatic Catalysis Enables Radical-Mediated Ketone Reduction in Ene-Reductases. Angew. Chem. Int. Ed. 58, 8714-8718 (2019).

34. Nakano, Y. et al. Photoenzymatic Hydrogenation of Heteroaromatic Olefins Using 'Ene'Reductases with Photoredox Catalysts. Angew. Chem. Int. Ed. 59, 10484-10488 (2020). 
35. Prier, C. K. Rankic, D. A. \& Macmillan, D. W. C. Visible Light Photoredox Catalysis with Transition Metal Complexes: Applications in Organic Synthesis. Chem. Rev. 113, 5322$5363(2013)$.

36. Abramovitz, A. S. \& Massey, V. Interaction of Phenols with Old Yellow Enzyme. Physical Evidence for Charge-Transfer Complexes. J. Biol. Chem. 251, 5327-5336 (1976).

37. Marshall, S. J. Krause, D., Blencowe, D. K. \& White, G. F. Characterization of Glycerol Trinitrate Reductase (NerA) and the Catalytic Role of Active-Site Residues. J. Bacteriol. 186, 1802-1810 (2004).

38. Steward, R. C. \& Massey, V. Potentiometric Studies of Native and Flavin-Substituted Old Yellow Enzyme. J. Biol. Chem. 260, 13639-13647 (1985).

39. Reetz, M. T. \& Carballeira, J. D. Iterative Saturation Mutagenesis (ISM) for Rapid Directed Evolution of Functional Enzymes. Nat. Protoc. 2, 891-903 (2007).

40. Nicholls, B. et al. Engineering a Non-Natural Photoenzyme for Improved Photon Efficiency. Angew. Chem. Int. Ed. Accepted article. DOI:10.1002/anie.202113842.

41. Bougioukou, D. J., Kille, S., Taglieber, A., Reetz, M. T. Directed Evolution of an Enantioselective Enoate-Reductase: Testing the Utility of Iterative Saturation Mutagenesis. Adv. Synth. Catal. 351, 3287-3305 (2009).

42. Sim, B. A., Griller, D. \& Wayner, D. D. M. Reduction Potentials for Substituted Benzyl Radicals: $\mathrm{pKa}$ Values for the Corresponding Toluenes. J. Am. Chem. Soc. 111, 754-755 (1989).

43. Sorigué, D. et al. Mechanism and Dynamics of Fatty Acid Photodecarboxylase. Science DOI: $10.1126 /$ science.abd5687. 
44. Weinberg, D. R. et al. Proton-Coupled Electron Transfer. Chem. Rev. 112, 4016-4093 (2012).

45. Collot, J., Humbert, N., Skander, M., Klein, G. \& Ward, T. R. Artificial Metalloenzymes for Enantioselective Catalysis: The Phenomenon of Protein Accelerated Catalysis. $J$. Organomet. Chem. 689, 4868-4871 (2004).

46. Kato, Y., Nagao, R., Noguchi, T. Redox Potential of the Terminal Quinone Electron Acceptor $\mathrm{Q}_{\mathrm{B}}$ in Photosystem II Reveals the Mechanism of Electron Transfer Regulation. Proc. Natl. Acad. Sci. USA 113, 620-625 (2016).

Acknowledgements The research reported here was supported by the National Institutes of Health National Institute of General Medical Sciences (R01 GM127703). We thank the Princeton Catalysis Initiative and Merck Co. for financial support. This work made use of the Cornell University NMR Facility, which is supported, in part, by the NSF though MRI Award CHE1531632. DGO acknowledges support from the Post-graduate Scholarships Doctoral Program of the Natural Sciences and Engineering Research Council of Canada. The authors thank Drs. Katie Meihaus, Phillip Clayman, Kyle Biegasiewicz and Yi Liu for assistance in preparing this manuscript. The authors thank Tianzhang Qiao for assistance in Density Functional Theory (DFT) calculations.

Author contributions Y.Y. and J.C. performed and analyzed the experiments. D.G.O. performed the transient absorption spectroscopy experiments. D.V. performed the MD simulations. Y.Y., J.C., C.K.P., G.D.S. and T.K.H. designed the experiments.

Competing interests The authors declare no competing interests. 